\title{
Medication adherence and beliefs about medication in elderly patients living alone with chronic diseases
}

This article was published in the following Dove Press journal:

Patient Preference and Adherence

\author{
Hwa Yeon Park ${ }^{1,2, *}$ \\ Sin Ae Seo ${ }^{2, *}$ \\ Hyeyoung Yoo ${ }^{2}$ \\ Kiheon Lee ${ }^{1-3}$ \\ 'Department of Family Medicine, \\ Seoul National University Bundang \\ Hospital, Seongnam, Republic of \\ Korea; ${ }^{2}$ Department of Community \\ Health Research, Seongnam Center \\ for Home Health Care, Seongnam, \\ Republic of Korea; ${ }^{3}$ Department of \\ Family Medicine, College of Medicine, \\ Seoul National University, Seoul, \\ Republic of Korea \\ *These authors contributed equally \\ to this work
}

Purpose: The aim of this study was to assess medication adherence and its related factors among elderly people living alone with chronic diseases using a conceptual framework with the Belief about Medicines Questionnaire and the Adherence to Refills and Medication ScaleKorean version.

Participants and methods: This was a cross-sectional study conducted in 3,326 elderly people living alone, who were enrolled in Seongnam Center for Home Health Care in South Korea. They completed validated questionnaires assessing their adherence and beliefs about medication in general.

Results: In attitudinal analysis using Belief about Medicines Questionnaire, 37.0\% of patients were accepting of medication (high necessity with low concerns), 49.7\% were ambivalent (high necessity with high concerns), $1.9 \%$ were skeptical (low necessity with high concerns), and $11.4 \%$ were indifferent (low necessity and low concerns). In multivariable analysis, we found that adherence was related to patients' beliefs about medication; compared with patients who were accepting of medication, those in the other three attitudinal groups had significantly lower adherence (indifferent, $p=0.003$; skeptical, $p=0.001$; ambivalent, $p<0.001$ ). Also, low adherence was associated with heavy burden of drug costs $(\beta=0.109 ; 95 \%$ CI $0.03,0.19)$, presence of drug side effects $(\beta=0.431 ; 95 \%$ CI $0.11,0.75)$, dissatisfaction with medication $(\beta=-0.626$; $95 \% \mathrm{CI}-0.77,-0.48)$, perceiving health status as poor $(\beta=-0.151 ; 95 \% \mathrm{CI}-0.27,-0.03)$, and receiving medical aid ( $\beta=0.655 ; 95 \%$ CI $0.42,0.89)$. Gender, age group, and number of prescribed medication were not associated with medication adherence.

Conclusion: To improve medication adherence of elderly living alone, it is essential to identify barriers to adherence, including their concerns and attitudes toward medications. These factors associated with adherence should be considered in further intervention studies.

Keywords: medication adherence, the elderly living alone, beliefs about medication, chronic diseases

\section{Introduction}

The elderly population aged 65 years and older is expected to grow from about 524 million in 2010 to about 1.5 billion in $2050 .{ }^{1}$ The number of people living alone seems to be higher with increased age. ${ }^{2}$ With an increase in the average life expectancy along with a change in the living arrangements, the number of elderly living alone will continue to increase. In the case of elderly living alone, family support is absent, resulting in a greater chance of sustained condition of chronic diseases, both physically and mentally. ${ }^{3-5}$ Indeed, the level of physical and mental health of elderly living alone is lower than those living with family members. ${ }^{3,6}$

Pharmacologic therapy is a key component in the treatment of chronic diseases. However, about $50 \%$ of patients with chronic diseases do not take medication
Correspondence: Kiheon Lee Department of Family Medicine, Seoul National University Bundang Hospital, 82, Gumi-ro 173 beon-gil, Bundang-gu, Seongnam-si, Gyeonggi-do, Republic of Korea

$\mathrm{Tel}+8231787780$ I

Fax +82 3। 7874834

Email keyhone2@snu.ac.kr 
as prescribed. ${ }^{7}$ In chronic diseases that require long-term treatment, low medication adherence usually leads to poor clinical outcome, drug-related side effects, and increased social health care costs. ${ }^{8,9}$ Moreover, it has been established that the proper use of medication is one of the important key factors for the self-management of most chronic diseases. ${ }^{10}$ Therefore, it is important to improve medication adherence in patients with chronic diseases to minimize early deaths and social burden. ${ }^{7,11}$

Medication adherence is influenced by many different factors, such as medication factors, patient factors, physician factors, system-based factors, and so on. ${ }^{12-14}$ Nonadherence behaviors broadly fall into two categories: 1) unintended nonadherence, which occurs due to forgetfulness, bad eyesight, and difficulty in movement and 2) intentional nonadherence, which occurs when medication is deliberately avoided, despite the ability to take the medication. ${ }^{15}$ Intentional nonadherence arises when a patient decides not to take the treatment as instructed. ${ }^{16}$ To increase medication adherence, it is critical to understand the underlying reason for nonadherence. Horne and Weinman proposed a recognition approach that is based on a necessity-concern framework. ${ }^{10}$ They showed that medication beliefs are associated with medication adherence, illustrating that beliefs in medication may offer greater predictability than any other clinical or social factors.

Among the elderly population, the characteristics between those living alone and those living with families are different. The elderly living alone was used as a control for comparison with the elderly living with families, but the control group was not studied as a sample. Also, given that this subpopulation is at a greater risk of negative health consequences, it is especially important to identify the factors affecting medication adherence in order to design an intervention strategy that can improve adherence for this group. Therefore, we tried to investigate the factors that influence medication adherence targeting elderly people living alone with chronic diseases.

\section{Participants and methods Study design and participants}

This cross-sectional study was conducted between June 1, 2016 and August 30, 2016. A total of 4,755 elderly people aged 65 years or older, who live alone and are registered in Seongnam Center for Home Health Care, were study subjects. Seongnam is one of the largest cities in Korea with a population of about 974,000 people. Trained nurses of the center visited the homes of patients to provide a general explanation of the purpose and contents of the study. Written informed consent was obtained from all individual participants included in the study. The inclusion criteria were as follows: 1) elderly individuals aged 65 years and older and 2) taking medication. People who were not able to participate in the survey due to visual impairment, hearing loss, or cognitive impairment (CI) were excluded. Also, people who were not at home during the study period or those who refused to participate in the study were not included. This study was approved by the Institutional Review Board of Seoul National University Bundang Hospital (institutional review board number B-1607/354-301).

\section{Demographics and clinical characteristics}

Participants were asked general questions on the survey, such as gender, age, marital status, education experience, religion, type of health insurance, and monthly income. The questionnaire also asked health-related questions, such as the number of chronic diseases, type of diseases, experience of drug-related side effects, medication satisfaction, number of prescribed drugs, burden of medication costs, and subjective health status.

\section{Medication adherence}

We used the Adherence to Refills and Medication Scale (ARMS) to assess medication adherence after obtaining approval of the original author. ARMS, developed by Kripalani et al, ${ }^{17}$ was a valid and reliable adherence scale and its Korean version (ARMS-K) was also verified among Korean adults with diabetes by Kim et al. ${ }^{18}$

The questionnaire consists of 12 questions, which are divided into two categories, adherence with taking medicines (eight items) and adherence with refilling of prescriptions (four items). Each item uses a four-point Likert response scale ( $1=$ none of the time, $4=$ all the time). Possible scores range from 12 to 48, with a lower score indicating greater adherence. Cronbach's $\alpha$ was found to be 0.801 for the internal consistency of ARMS-K by Kim et al.

\section{Belief about medicines}

We used the Belief about Medicines Questionnaire (BMQ) developed by Horne et al to assess the beliefs of patients about medication. ${ }^{19}$ Four bilingual speakers, both English and Korean, completed the Korean version via the translation and back translation process. This questionnaire comprised two five-item scales assessing the beliefs of patients on the necessity of the prescribed medication for controlling their illness and their concerns about the potential adverse consequences of taking it. ${ }^{20}$ Each item was scored on a five-point 
Likert response scale ( $1=$ strongly disagree, $3=$ uncertain, $5=$ strongly agree). Two five-item scales indicating necessity and concerns were ranged from 5 to 25 .

\section{Concepts and framework of patients' attitudes toward medications}

The concepts of a relationship between beliefs about medication and medication adherence are shown in Figure 1. Patients' attitudes toward medication that were assessed using BMQ with the level of necessity and concerns are presented in Figure 2. As in previous studies, 15, which was the midpoint on this scale, was used as a criterion for dividing the group into high and low necessity, as well as into high and low concern. ${ }^{20,21}$ There were four divisions in patient attitude: high necessity and low concern were classified as "accepting"; high necessity and high concern as "ambivalent"; low necessity and high concern as "skeptical"; and low necessity and low concern as "indifferent".

\section{Data analysis}

Descriptive analysis was performed to evaluate the general and clinical characteristics of participants. ARMS-K was analyzed using the means and standard deviation of each item. Several statistical techniques were used to analyze the relationship between beliefs about medication and adherence. The Student's $t$-test and one-way analysis of variance were used to examine the differences in the degree of adherence according to the demographic variables and clinical characteristics. To identify the difference in medication adherence among four attitudinal groups, one-way analysis of variance and post hoc test were used between groups; $p$-value of 0.017 was considered to indicate statistical significance (accounting for a Scheffe correlation). We used the chi-square test and correlation test to determine whether two variables were independent. Multivariable regression analysis was performed to investigate the factors that influence medication adherence. We controlled for independent variables that were significantly associated with medication adherence in univariate analysis or that we judged to be important based on other research: age, gender, attitudes of beliefs about medication, burden of drug costs, the presence of drug-related side effects, medication satisfaction, number of drugs, subjective health status, and type of health insurance. A $p$-value of $<0.05$ was considered statistically significant. ${ }^{13,22,23}$ All data analyses were performed using STATA software, Version 14.0 (StataCorp LP, College Station, TX, USA).

\section{Results}

Among the 4,755 elderly individuals living alone and registered at Seongnam Center for Home Health Care, 356 were excluded as they were either not home at the time of survey or refused to participate; an additional 559 patients were excluded as they were not on any medication. Of the remaining 3,840 patients, 514 were excluded for inappropriate responses in specific items including ARMS-K and BMQ.

As a result, a total of 3,326 patients were included for the analysis. Of them, $83.7 \%$ were women. Almost half of the participants $(55.2 \%)$ were between the ages of 75 and 84 years. Moreover, 79.7\% were widows, 42.7\% were not educated, and $64.1 \%$ answered that they were religious. Two thirds had a monthly income of between 300,000 and 600,000 Korean won (KRW), which was approximately between 267 and 535 USD. Also, 24.8\% were prescribed with more than 10 drugs. Those supported by medical aid program constituted $47.8 \%$ of the study population (Table 1).

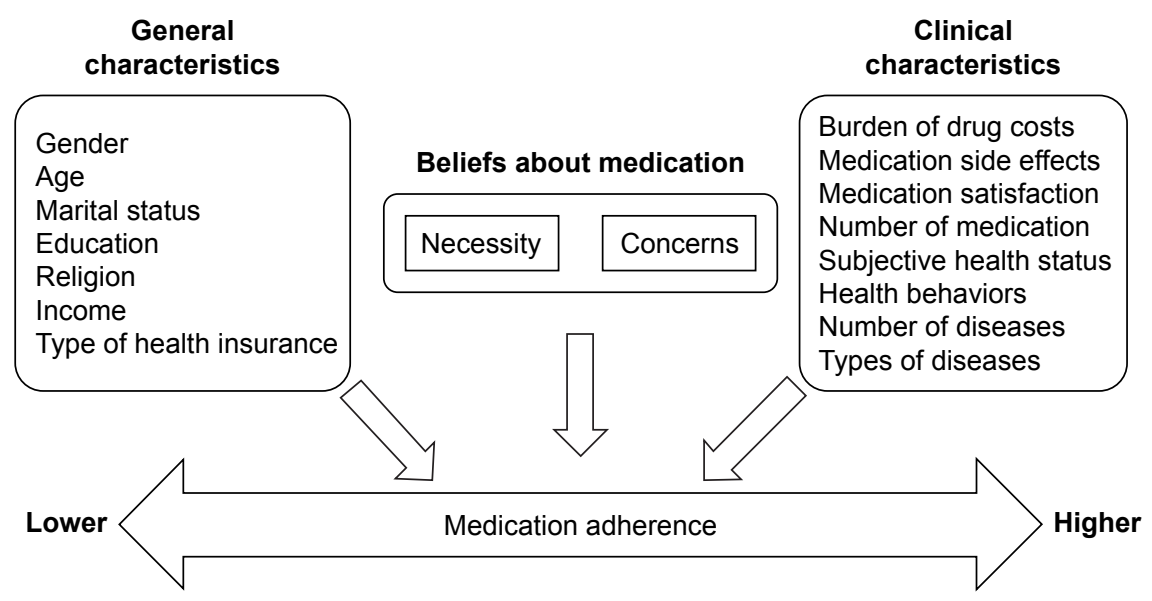

Figure I Relationship between beliefs about medication and medication adherence. 


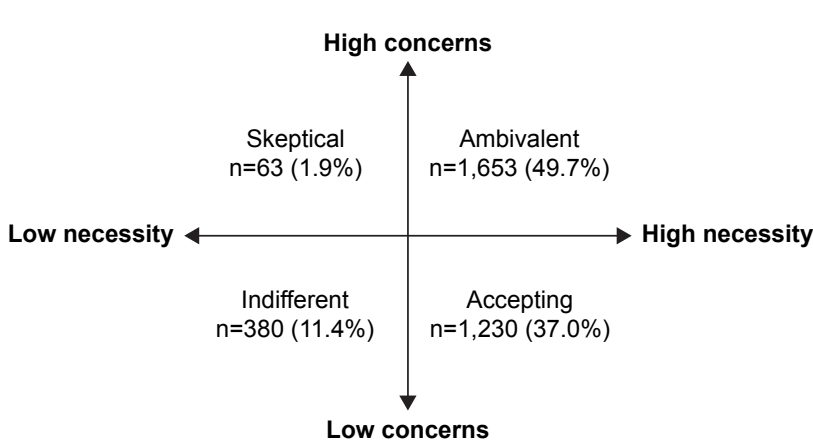

Figure 2 Framework of patients' attitudes and beliefs about medication.

Of the 12 questions in the ARMS-K, the question regarding whether the patient planned ahead of time for medication refill before running out showed the highest percentage $(65.6 \%)$, indicating lowest medication adherence. Conversely, we observed lowest percentage (4.6\%) highest medication adherence - for the question regarding whether the patient postponed medication refill due to high burden of drug costs. The average total score of all items was 16.08, with a standard deviation of 2.78 and a Cronbach's $\alpha$ of 0.73 (Table 2).

On dividing the study population into groups depending on their attitudes toward medication, 49.7\% (1,653 patients) were "ambivalent", $37.0 \%$ (1,230 patients) were "accepting", 11.4\% (380 patients) were "indifferent", and $1.9 \%$ were skeptical (63 patients), as shown in Figure 2. Comparisons of medication adherence by ARMS were made across these four attitudinal groups. Mean total score of ARMS was highest in "skeptical" group (17.32 \pm 3.70$)$ and lowest in "accepting" group (15.66 \pm 2.23$)$. There were significant differences among the four groups $(F=16.23$, $p<0.001)$. Also, the "accepting" group reported significantly higher adherence than the "indifferent" group, "skeptical" group, and "ambivalent" group (all $p<0.001$; Table 3).

According to a univariate analysis with respect to determining the factors that affect medication adherence, attitudes toward medication, presence of drug-related side effect, and type of health insurance were associated with low adherence. Also, an increase in medication satisfaction, subjective health status, and number of drugs resulted in low adherence. In a multivariable regression, medication adherence was higher in patients who were accepting of medication, than in patients who were indifferent $(p=0.003)$, skeptical $(p=0.001)$, and ambivalent $(p<0.001)$. Heavy burden of drug cost $(\beta=0.109 ; 95 \%$ CI $0.03,0.19)$ and perceived health status as poor $(\beta=-0.151 ; 95 \% \mathrm{CI}-0.27,-0.03)$ were associated with low adherence. Patients who experienced drug-related side effects $(\beta=0.431 ; 95 \%$ CI $0.11,0.75)$ and
Table I Baseline characteristics of participants $(\mathrm{N}=3,326)$

\begin{tabular}{|c|c|}
\hline & $\mathbf{N}(\%)$ \\
\hline \multicolumn{2}{|l|}{ Gender } \\
\hline Male & $543(16.3)$ \\
\hline Female & $2,783(83.7)$ \\
\hline \multicolumn{2}{|l|}{ Age group } \\
\hline $65-74$ & $904(27.2)$ \\
\hline $75-84$ & $\mathrm{I}, 836(55.2)$ \\
\hline$\geq 85$ & $586(17.6)$ \\
\hline \multicolumn{2}{|l|}{ Marital status } \\
\hline Never married & $143(4.4)$ \\
\hline Widowed & $2,621(79.7)$ \\
\hline Divorced & $405(12.3)$ \\
\hline Separated & $119(3.6)$ \\
\hline \multicolumn{2}{|l|}{ Education } \\
\hline Uneducated & $\mathrm{I}, 405(42.7)$ \\
\hline Elementary school & $1,089(33.1)$ \\
\hline Middle school & $400(12.1)$ \\
\hline High school or more & $400(12.1)$ \\
\hline \multicolumn{2}{|l|}{ Religion } \\
\hline Yes & $2,127(64.1)$ \\
\hline \multicolumn{2}{|l|}{ Number of medication } \\
\hline $1-4$ & $\mathrm{I}, 342(40.3)$ \\
\hline $5-9$ & $\mathrm{I}, \mathrm{I} 60(34.9)$ \\
\hline$\geq 10$ & $824(24.8)$ \\
\hline \multicolumn{2}{|c|}{ Income (per month), Korean Won } \\
\hline$<300,000$ & $390(11.7)$ \\
\hline $300,000-599,999$ & $2,286(68.7)$ \\
\hline $600,000-899,999$ & $446(13.4)$ \\
\hline$\geq 900,000$ & $204(6.2)$ \\
\hline \multicolumn{2}{|l|}{ Health insurance } \\
\hline National Health Insurance & $\mathrm{I}, 727(52.2)$ \\
\hline Medical Aid & I,583 (47.8) \\
\hline \multicolumn{2}{|l|}{ Type of diseases ${ }^{a}$} \\
\hline Hypertension & $2,496(75.1)$ \\
\hline Diabetes mellitus & $977(29.4)$ \\
\hline Arthritis & $\mathrm{I}, 080(32.5)$ \\
\hline Osteoporosis & $437(13.1)$ \\
\hline \multicolumn{2}{|l|}{ Number of chronic diseases } \\
\hline I & $755(23.4)$ \\
\hline 2 & $\mathrm{I}, \mathrm{I} 4 \mathrm{I}(35.4)$ \\
\hline 3 & $810(25.2)$ \\
\hline$\geq 4$ & $514(16.0)$ \\
\hline
\end{tabular}

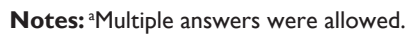

were dissatisfied with treatment $(\beta=-0.626 ; 95 \% \mathrm{CI}-0.77$, -0.48 ) had lower adherence. Receiving medical aid was also significantly related with low medication adherence ( $\beta=0.655 ;$ 95\% CI 0.42, 0.89; Table 4). Gender, age group, and number of prescribed medication were not associated with medication adherence.

\section{Discussion}

This study investigated medication adherence in elderly individuals living alone. In previous studies on elderly people with chronic diseases, high need or low concerns 
Table 2 Distribution of ARMS

\begin{tabular}{|c|c|c|c|}
\hline Items & Mean $\pm \mathbf{S D}^{\mathbf{a}}$ & $\begin{array}{l}\text { None of } \\
\text { the time (\%) }\end{array}$ & $\begin{array}{l}\text { Sometimes, often or } \\
\text { all of the time (\%) }\end{array}$ \\
\hline \multicolumn{4}{|l|}{ Medication taking } \\
\hline I. Forget to take your medicine? & $1.39 \pm 0.56$ & 64.3 & 35.7 \\
\hline 2. Decide not to take your medicine? & $1.12 \pm 0.39$ & 90.6 & 9.4 \\
\hline 5. Skip a dose of your medicine before you go to the doctor? & $1.13 \pm 0.40$ & 88.3 & 11.7 \\
\hline 6. Miss taking your medicine when you feel better? & $1.16 \pm 0.46$ & 87.0 & 13.0 \\
\hline 7. Miss taking your medicine when you feel sick? & $1.11 \pm 0.37$ & 91.1 & 8.9 \\
\hline 8. Miss taking your medicine when you are careless? & $1.32 \pm 0.53$ & 70.6 & 29.4 \\
\hline $\begin{array}{l}\text { 9. Change the dose of your medicines to suit your needs } \\
\text { (like when you take more of less pills than you're supposed to)? }\end{array}$ & $1.09 \pm 0.35$ & 93.0 & 7.0 \\
\hline $\begin{array}{l}\text { 10. Forget to take your medicine when you are supposed } \\
\text { to take it more than once a day? }\end{array}$ & $1.23 \pm 0.5 \mathrm{I}$ & 80.5 & 19.5 \\
\hline \multicolumn{4}{|l|}{ Prescription refill } \\
\hline 3. Forget to get prescriptions filled? & $1.08 \pm 0.31$ & 92.7 & 7.3 \\
\hline 4. Run out of medicine? & $1.08 \pm 0.32$ & 92.6 & 7.4 \\
\hline $\begin{array}{l}\text { II. Put off refilling your medicines because they cost } \\
\text { too much money? }\end{array}$ & $1.06 \pm 0.32$ & 95.4 & 4.6 \\
\hline 12. Plan ahead and refill your medicines before they run out? ${ }^{\text {b }}$ & $3.32 \pm 1.10$ & 65.6 & 34.4 \\
\hline
\end{tabular}

Notes : aPossible range, I-4. ' This item was reverse coded. The included ARMS subscales are reproduced with permission from Kripalani S, Risser J, Gatti ME, Jacobson TA Development and evaluation of the adherence to refills and medications scale (ARMS) among low-literacy patients with chronic disease. Value Health. 2009; I2(I):I I8-I23. Copyright (C) 2009 Emory University. ${ }^{17}$

Abbreviations: ARMS, Adherence to Refills and Medication Scale; SD, standard deviation.

for medication were associated with high adherence. ${ }^{24-26}$ These findings are consistent with our findings in elderly individuals living alone. One explanation for accordance is that the elderly groups in previous studies naturally included people who were living alone, which were the subjects and focus of this investigation.

In a previous study, Morisky et al found that knowledge, patient satisfaction, coping skills, stress level, and medication complexity are associated with adherence. ${ }^{27}$ In addition, Rolnick et al found that factors such as gender, race, age, education level, and income are also likely to have an effect on medication adherence. ${ }^{28}$ However, Horne and Weinman

Table 3 The difference of medication adherence between attitudinal groups ${ }^{\mathrm{a}}$

\begin{tabular}{lll}
\hline $\begin{array}{l}\text { Attitudes toward } \\
\text { medications }^{\mathbf{b}}\end{array}$ & $\begin{array}{l}\text { Mean ARMS } \\
\text { score (SD) }\end{array}$ & p-value \\
\hline Accepting & $\mathrm{I} 5.66(2.23)$ & $<0.00 \mathrm{I}$ \\
Indifferent & $\mathrm{I} 6.36(3.72)$ & \\
Skeptical & $\mathrm{I} 7.32(3.70)$ & \\
Ambivalent & $\mathrm{I} 6.30(2.96)$ & $<0.00$ I \\
Accepting vs indifferent & & $<0.00$ I \\
Accepting vs skeptical & & $<0.00$ I \\
Accepting vs ambivalent & & 0.084 \\
Indifferent vs skeptical & & 0.969 \\
Indifferent vs ambivalent & & $0.03 \mathrm{I}$ \\
Skeptical vs ambivalent & & \\
\hline
\end{tabular}

Notes: a Using one-way analysis of variance and post hoc test. U Using Belief about Medicines Questionnaire scores with the level of necessity and concerns. 'Adherence to Refills and Medication Scale.

Abbreviations: ARMS, Adherence to Refills and Medication Scale; SD, standard deviation. found that medication belief may be a more powerful predictor of medication adherence than gender, education experience, number of medications, and sociodemographic factors. ${ }^{10}$

In this study, we discovered that patients with high need and low concern about medication (the accepting group) had higher adherence than patients with high need and high concern (the ambivalent group). In other words, our results were in line with Horne et al's study, highlighting that beliefs about medication may indeed be a powerful predictor. ${ }^{21}$ Patients often have concerns about taking medication out of fear of drug dependence or side effects. ${ }^{22,29}$ Therefore, health care

Table 4 Multivariable analysis with medication adherence

\begin{tabular}{|c|c|c|c|}
\hline Variables & $\begin{array}{l}\text { Multivariable } \\
\beta \text { coefficient }\end{array}$ & $p$-value & $\begin{array}{l}95 \% \text { confidence } \\
\text { interval }\end{array}$ \\
\hline \multicolumn{4}{|c|}{ Attitudes toward medications ${ }^{a}$} \\
\hline Accepting & Reference & & \\
\hline Indifferent & 0.487 & 0.003 & $0.17,0.81$ \\
\hline Skeptical & 1.161 & 0.001 & $0.47,1.85$ \\
\hline Ambivalent & 0.371 & $<0.001$ & $0.17,0.58$ \\
\hline Burden of drug costs & 0.109 & 0.006 & $0.03,0.19$ \\
\hline \multicolumn{4}{|l|}{ Medication side effects } \\
\hline No & Reference & & \\
\hline Yes & 0.431 & 0.008 & $0.11,0.75$ \\
\hline Medication satisfaction & -0.626 & $<0.001$ & $-0.77,-0.48$ \\
\hline Subjective health status & -0.151 & 0.015 & $-0.27,-0.03$ \\
\hline \multicolumn{4}{|c|}{ Health insurance } \\
\hline National health insurance & Reference & & \\
\hline Medical aid & 0.655 & $<0.001$ & $0.42,0.89$ \\
\hline
\end{tabular}

Note: ${ }^{a}$ Using Belief about Medicines Questionnaire scores with the level of necessity and concerns. 
professionals should be aware of these common concerns and make sure to maintain good communication with their patients to address such concerns.

Among common concerns, we found that drug-related adverse events particularly contributed to lower adherence. Hence, as a professional, it is important to share the known side effects of the prescribed drugs and to educate patients of ways to recognize and cope with them, enabling their confidence. In addition, aside from the adverse side effects of drugs, the use of complementary alternative medicines can complicate the treatment regimen. As the number of drugs to take increases, patients may be overwhelmed and psychologically burdened. Therefore, after assessing the side effects of the prescribed drugs, to better understand the reasons for lower adherence, it is important to determine whether patients are taking other medication, including complementary alternative medicines. It causes lower medication adherence in chronic diseases. ${ }^{30,31}$

Medication satisfaction was another key factor of predicting medication adherence. Factors affecting medication satisfaction were as follows: drug-related side effects, drug effectiveness, and flexible medication times. ${ }^{32}$ Therefore, it is important for patients to know the specific purpose of taking the medication, such as prevention, symptom relief, and treatment. To maximize the effectiveness of medication, it is essential for patients to comply with prescriptions, such as dosage regimen, method, medication time, and so on. Efforts to minimize side effects and inconvenience of taking medication are needed to improve medication satisfaction. Moreover, research on the shape, design, and color of the drugs preferred by elderly patients should be considered.

We found that medication adherence was related to the type of health insurance. More than $48 \%$ of participants received government medical aid in this study. Medication adherence in patients with government medical aid was lower than that in patients with national health insurance. It is worth noting that government medical aid program is a part of the social welfare program in Korea and is for those with low socioeconomic status, suggesting that low socioeconomic status may be associated with low medication adherence, although there was no direct relationship between low income level and medication adherence in our study. People with low socioeconomic status are likely to have inadequate health behaviors and poor access to medical services, which may lead to low medication adherence, thereby resulting in poor overall health-related quality of life. ${ }^{33}$

This study has several limitations. We only used a selfreported questionnaire to evaluate medication adherence. Therefore, it is possible that medication adherence was reported to be higher than actual adherence. A combination of different assessment methods, such as pill count, medication monitoring system, or pharmacy claims data, might be useful to assess accurate medication adherence. ${ }^{34}$

Second, among the possible associated factors, we were unable to identify mild CI that affected medication nonadherence in the elderly population with chronic diseases. Cognitive processes affect managing medications. In a recent review article, it has shown that older adults with CI report lower adherence compared to cognitively intact people. ${ }^{35}$ Even older adults with mild $\mathrm{CI}$ have poor adherence. ${ }^{36,37} \mathrm{We}$ excluded patients with CI or dementia at the level of recruitment. However, the possibility of mild CI still remains, and memory as a barrier to adherence is important.

Finally, the included subjects were registered in the Center for Home Health Care, regularly receiving health care services. Hence, this study population may not be representative of the general population of elderly people living alone with chronic diseases. Future comparative studies are required to compare between elderly people living alone with home health care service and those without home health care service.

This study highlights the perspective that patients' beliefs about medication influence medication adherence, thus influencing whether they partake in the active role of disease management. Despite the effectiveness of medicine, without proper adherence on the part of patients, chronic disease management becomes difficult and challenging. To promote better adherence, it is critical for patients to have a better understanding of their diseases paired with a strong belief about their prescribed medication. In addition, these barriers to adherence of the elderly living alone should be considered in further intervention studies.

\section{Acknowledgment}

We give thanks to Hyejin Cho who provided assistance with constructing the questionnaires and all the visiting nurses of Seongman Center for Home Health Care who collected data for this research.

\section{Disclosure}

The authors report no conflicts of interest in this work.

\section{References}

1. World Health Organization. Global Health and Aging. Geneva: World Health Organization Press; 2011.

2. Administration for Community of Living [homepage on the Internet]. A Profile of Older Americans: 2016; [updated 2017 August 14]. Available from: https://www.acl.gov/aging-and-disability-in-america/data-andresearch/profile-older-americans. Accessed August 20, 2017. 
3. Kharicha K, Iliffe S, Harari D, Swift C, Gillmann G, Stuck AE. Health risk appraisal in older people 1: are older people living alone an "at-risk" group? Br J Gen Pract. 2007;57(537):271-276.

4. Barat I, Andreasen F, Damsgaard EM. Drug therapy in the elderly: what doctors believe and patients actually do. Br J Clin Pharmacol. 2001;51(6):615-622.

5. McInnis GJ, White JH. A phenomenological exploration of loneliness in the older adult. Arch Psychiatr Nurs. 2001;15(3):128-139.

6. Lau DT, Kirby JB. The relationship between living arrangement and preventive care use among community-dwelling elderly persons Am J Public Health. 2009;99(7):1315-1321.

7. Sabaté E. Adherence to Long-Term Therapies: Evidence for Action. Geneva: World Health Organization Press; 2003.

8. Ownby RL. Medication adherence and cognition medical, personal and economic factors influence level of adherence in older adults. Geriatrics. 2006;61(2):30-35.

9. World Health Organization. Noncommunicable Diseases Country Profiles 2011. Geneva: World Health Organization Press; 2011.

10. Horne R, Weinman J. Patients' beliefs about prescribed medicines and their role in adherence to treatment in chronic physical illness. J Psychosom Res. 1999;47(6):555-567.

11. Dunbar-Jacob J, Erlen JA, Schlenk EA, Ryan CM, Sereika SM, Doswell WM. Adherence in chronic disease. Annu Rev Nurs Res. 2000; 18:48-90.

12. van der Laan DM, Elders PJM, Boons CCLM, Beckeringh JJ, Nijpels G, Hugtenburg JG. Factors associated with antihypertensive medication non-adherence: a systematic review. J Hum Hypertens. 2017;31(11): 687-694.

13. Yap AF, Thirumoorthy T, Kwan YH. Systematic review of the barriers affecting medication adherence in older adults. Geriatr Gerontol Int. 2016;16(10):1093-1101.

14. Hugtenburg JG, Timmers L, Elders PJ, Vervloet M, van Dijk L. Definitions, variants, and causes of nonadherence with medication a challenge for tailored interventions. Patient Prefer Adherence. 2013 7:675-682.

15. Home R, Petrie K, Weinman J. Representations of Medication and Treatment: Advances in Theory and Measurement. Harwood Academic London; 1997.

16. Weintraub M. Compliance in the elderly. Clin Geriatr Med. 1990;6(2): 445-452.

17. Kripalani S, Risser J, Gatti ME, Jacobson TA. Development and evaluation of the adherence to refills and medications scale (ARMS) among low-literacy patients with chronic disease. Value Health. 2009;12(1): $118-123$.

18. Kim CJ, Park E, Schlenk EA, Kim M, Kim DJ. Psychometric evaluation of a Korean version of the adherence to refills and medications scale (ARMS) in adults with type 2 diabetes. Diabetes Educ. 2016;42(2): 188-198.

19. Horne R, Weinman J, Hankins M. The beliefs about medicines questionnaire: the development and evaluation of a new method for assessing the cognitive representation of medication. Psychol Health. 1999;14(1):1-24.

20. Kim SB, Kim KO, Jang BI, et al. Patients' beliefs and attitudes about their treatment for inflammatory bowel disease in Korea. J Gastroenterol Hepatol. 2016;31(3):575-580.
21. Horne R, Parham R, Driscoll R, Robinson A. Patients' attitudes to medicines and adherence to maintenance treatment in inflammatory bowel disease. Inflamm Bowel Dis. 2009;15(6):837-844.

22. Mukhtar O, Weinman J, Jackson SH. Intentional non-adherence to medications by older adults. Drugs Aging. 2014;31(3):149-157.

23. Unni EJ, Farris KB. Unintentional non-adherence and belief in medicines in older adults. Patient Educ Couns. 2011;83(2):265-268.

24. Schuz B, Marx C, Wurm S, et al. Medication beliefs predict medication adherence in older adults with multiple illnesses. J Psychosom Res. 2011;70(2):179-187.

25. Sirey JA, Weinberger MI, Greenfield A, Bruce ML. Medication beliefs and self-reported adherence among community-dwelling older adults. Clin Ther. 2013;35(2):153-160.

26. Rajpura JR, Nayak R. Role of illness perceptions and medication beliefs on medication compliance of elderly hypertensive cohorts. $J$ Pharm Pract. 2014;27(1):19-24.

27. Morisky DE, Ang A, Krousel-Wood M, Ward HJ. Predictive validity of a medication adherence measure in an outpatient setting. $J$ Clin Hypertens (Greenwich). 2008;10(5):348-354.

28. Rolnick SJ, Pawloski PA, Hedblom BD, Asche SE, Bruzek RJ. Patient characteristics associated with medication adherence. Clin Med Res. 2013;11(2):54-65

29. Markotic F, Cerni Obrdalj E, Zalihic A, et al. Adherence to pharmacological treatment of chronic nonmalignant pain in individuals aged 65 and older. Pain Med. 2013;14(2):247-256.

30. Alfian S, Sukandar H, Arisanti N, Abdulah R. Complementary and alternative medicine use decreases adherence to prescribed medication in diabetes patients. Ann Trop Med Public Health. 2016;9(3):174-179.

31. Owen-Smith A, Diclemente R, Wingood G. Complementary and alternative medicine use decreases adherence to HAART in HIV-positive women. AIDS Care. 2007;19(5):589-593.

32. Atkinson MJ, Sinha A, Hass SL, et al. Validation of a general measure of treatment satisfaction, the treatment satisfaction questionnaire for medication (TSQM), using a national panel study of chronic disease. Health Qual Life Outcomes. 2004;2:12.

33. Hong JY, Kim GJ. Difference in health-related quality of life between medical aid beneficiaries and health insurance beneficiaries using the community health survey. J Korea Content Assoc. 2016;16(5):477-487.

34. Giardini A, Martin MT, Cahir C, et al. Toward appropriate criteria in medication adherence assessment in older persons: position paper. Aging Clin Exp Res. 2016;28(3):371-381.

35. Smith D, Lovell J, Weller C, et al. A systematic review of medication non-adherence in persons with dementia or cognitive impairment PLoS One. 2017;12(2):e0170651.

36. Campbell NL, Zhan J, Tu W, et al. Self-reported medication adherence barriers among ambulatory older adults with mild cognitive impairment. Pharmacotherapy. 2016;36(2):196-202.

37. Hayes TL, Larimer N, Adami A, Kaye JA. Medication adherence in healthy elders: small cognitive changes make a big difference. J Aging Health. 2009;21(4):567-580.
Patient Preference and Adherence

\section{Publish your work in this journal}

Patient Preference and Adherence is an international, peer-reviewed, open access journal that focuses on the growing importance of patient preference and adherence throughout the therapeutic continuum. Patient satisfaction, acceptability, quality of life, compliance, persistence and their role in developing new therapeutic modalities and compounds to optimize

\section{Dovepress}

clinical outcomes for existing disease states are major areas of interest for the journal. This journal has been accepted for indexing on PubMed Central. The manuscript management system is completely online and includes a very quick and fair peer-review system, which is all easy to use. Visit http://www. dovepress.com/testimonials.php to read real quotes from published authors. 